\title{
Effects of cardiopulmonary bypass on the development of lymphopenia and sepsis after cardiac surgery in children with congenital cardiopathy
}

\author{
ROSALINDA JIMÉNEZ-AGUILAR ${ }^{1,2}$, NORMA SÁNCHEZ-ZAUCO ${ }^{3}$, \\ REYNALDO TIBURCIO-FELIX ${ }^{4}$, JORGE ZAVALA LÓPEZ ${ }^{5}$, ALEJANDRO SOLANO-GUTIÉRREZ ${ }^{6}$, \\ CARLOS RIERA $^{5}$, ELBA REYES-MALDONADO ${ }^{2}$ and CARMEN MALDONADO-BERNAL ${ }^{7}$ \\ ${ }^{1}$ Terapia Intensiva, Unidad Médica de Alta Especialidad, Hospital General Gaudencio González de la Garza, \\ Centro Médico Nacional ‘La Raza’, IMSS, Mexico City C.P. 02990; ²Departamento de Morfología, \\ Laboratorio de Bacteriología, Escuela Nacional de Ciencias Biológicas, Instituto Politécnico Nacional,
}

Mexico City C.P. $11350 ;{ }^{3}$ División de Auxiliares de Diagnóstico y Tratamiento UMAE, Hospital de Especialidades, Centro Médico Nacional-Siglo XXI, IMSS, Mexico City C.P. 06725; ${ }^{4}$ Departamento de Genética y Biología Molecular,

Centro de Investigación y de Estudios Avanzados del Instituto Politécnico Nacional, Mexico City C.P. 07240;

${ }^{5}$ Departamento de Circulación Extracorporea, Hospital de Pediatría del Centro Médico Nacional SXXI;

${ }^{6}$ Servicio de Cirugía Cardiovascular, Hospital de Cardiología del Centro Médico Nacional Siglo XXI, IMSS, Unidad Médica de Alta Especialidad, Mexico City C.P. 06725; ${ }^{7}$ Laboratorio de Investigación en Inmunología y Proteómica, Hospital Infantil de México Federico Gómez, Mexico City C.P. 06171, México

Received July 23, 2018; Accepted May 30, 2019

DOI: 10.3892/etm.2019.8241

\begin{abstract}
The objective of the present study was to investigate whether lymphopenia occurring after heart surgery with cardiopulmonary bypass (CPB) is related to apoptosis and or sepsis in children. The design was a prospective cohort study in a third level care hospital in Mexico City. In total, 68 children (31 girls and 37 boys) with congenital cardiopathy who needed corrective cardiac surgery with or without CPB were included. The samples were obtained from central blood before, immediately after and $24 \mathrm{~h}$ after surgery. Complete blood counts and lymphocyte apoptosis were analyzed. Systemic inflammatory response syndrome (SIRS), sepsis and the type of microorganism were recorded. A total of 53 patients received $\mathrm{CPB}$ and 15 did not. Lymphocyte count decreased after surgery in both groups $(\mathrm{P}<0.001)$. However, neutrophil count increased markedly in both groups. Apoptosis of B $\left(\mathrm{CD} 19^{+}\right)$ lymphocytes was higher in the non-CPB group (14, 2 and $21 \%$ before, immediately after and $24 \mathrm{~h}$ after surgery, respectively) than the CPB group (0, 2 and $3 \%$, respectively), but apoptosis
\end{abstract}

Correspondence to: Dr Carmen Maldonado-Bernal, Laboratorio de Investigación en Inmunología y Proteómica, Hospital Infantil de México Federico Gómez, 162 Dr Márquez Street Col. Doctores, Mexico City C.P. 06171, México

E-mail: cmaldobe@yahoo.com

Key words: cardiopulmonary derivation, child cardiac surgery, cardiopulmonary bypass, lymphopenia, sepsis, apoptosis of cytotoxic $\mathrm{T}$ lymphocytes $\left(\mathrm{CD}^{+}\right)$was higher in the $\mathrm{CPB}$ group (5, 4 and $3 \%$ before, immediately after and $24 \mathrm{~h}$ after surgery, respectively) than in the non-CPB group $(2,3$ and $2 \%$, respectively). However, the extent of apoptosis of $\mathrm{T}$ and $\mathrm{B}$ lymphocytes after surgery did not differ between groups. The CPB group had more complications than the non-CPB group [38 (71.7\%) vs. $9(60.0 \%)]$. In conclusion, the decrease in lymphocyte count may be related to apoptosis of cytotoxic $\mathrm{T}$ lymphocytes in children receiving cardiac surgery with $\mathrm{CPB}$ and to apoptosis of B lymphocytes in those not receiving CPB. The decreased lymphocyte counts in both groups suggested that CPB is not the main cause of this decrease. Children who received $\mathrm{CPB}$ during surgery had more complications, such as sepsis and cardiogenic shock than did those who did not receive $\mathrm{CPB}$.

\section{Introduction}

In Mexico City, for each 1,000 live births, 16.5 to 20 are infants born with congenital cardiac disease. Using birthdate information, we have calculated that 10,000 to 12,000 infants are born with some type of cardiac malformation each year. Mortality caused by congenital cardiopathy represents the sixth leading cause of death in the first year of life and has a 3.2\% rate; it represents the ninth leading cause of death in children aged 1 to 4 years (1.6\% rate), and the 14th leading cause of death in children aged over 5 years (1.1\% rate) (1).

Cardiac correction represents the first place in pediatric surgery. Despite major advances in the past two decades, sepsis is potential problem after surgery and can lead to death. In the Pediatric Hospital at the Instituto Mexicano del Seguro 
Social (National Medical Center), around 100 children per year are seen with congenital cardiac malformations. Most of these infants require cardiac surgery, and more than $60 \%$ require cardiopulmonary bypass (CPB). Sixty percent of those who receive CPB may develop an infection (2).

Infants undergoing heart surgery are at increased risk for developing immunosuppression and severe infection (2). These children may also develop various complications caused by the physiological response to ischemia-reperfusion damage (3-4). Many researchers have considered that this damage may be generated by $\mathrm{CPB}$, and some have reported lymphopenia after CPB possibly caused by apoptosis of lymphocytes (5-7). However, only a few studies have reported lymphopenia in children (2-8). Patients who develop lymphopenia often display a characteristic systemic inflammatory response syndrome (SIRS), which may result from the infection itself or may be a secondary response of damage-associated molecular patterns to the original event, such as surgery or hypoxia $(9,10)$.

Bacteremia can cause systemic inflammatory response and sepsis (11). When bacteria reach the blood, a set of mechanisms is activated to eliminate the microorganisms through the release of proinflammatory mediators and chemical agents. These agents stimulate the immune system to act at the vascular endothelial level, which can cause damage to blood vessels and increase permeability. This response activates a plasma cascade of powerful vasoconstrictors, such as cytokines, interleukin 1 (IL-1 $\beta$ ), IL-6, cyclooxygenase, and lipoxygenase, which are also involved in the adaptive immune response and send signals to stimulate apoptosis and produce myocardial depression.

These changes can cause shock, which activates the coagulation cascade and the complement cascade, and can subsequently cause thrombosis in small vessels and hemorrhage at different levels. This plasma cascade simultaneously stimulates several chemical agents, which respond to tissue damage, activation and recruitment of cells such as macrophages, neutrophils, and lymphocytes, and release of inflammatory mediators $(12,13)$.

Immune cells display membrane receptors called Toll-like receptors (TLRs). TLRs represent a group of transmembrane proteins that function as pattern-recognition receptors by detecting and responding to microbial ligands, which are defined as pathogen-associated molecular patterns (PAMPs) $(14,15)$. PAMPs are involved in the processes of bacteremia and endotoxemia, promote the release of systemic proinflammatory cytokines, and worsen damage caused by the infection. Bacterial cell wall products, such as lipopolysaccharide (LPS), lipoteichoic acid, and peptidoglycans trigger expression of many inflammatory cytokines in monocytes. LPS, also known as endotoxin, is a major constituent of the outer membrane of Gram-negative bacteria; LPS elicits an immune reaction that is responsible for many of the harmful effects in patients with septic shock (15). This signal pathway activates a variety of transcription factors, such as nuclear factor $\kappa \mathrm{B}(\mathrm{NF}-\kappa \mathrm{B})$, which induces the production of inflammatory mediators that maintain the inflammatory cycle $(16,17)$.

It is clear that LPS cannot be responsible for all clinical features of sepsis and those other factors must also contribute to sepsis (18). The major wall components of pathogenic agents and nonpathogenic agents are considered to contribute to the development of sepsis, septic shock, and multiple organ dysfunction syndrome (MODS) (19). Similar to LPS, they can interact with TLR4 and CD14 to initiate signal transduction pathways that lead to NF-kB activation $(20,21)$. Activation of SIRS, which is generally chaotic, causes endothelial damage. Damage to the systemic circulation and microcirculation can cause mitochondrial discharge and increased extraction and consumption of oxygen. These changes can cause tissue hypoxia, and hyperlactatemia. Hypoxia and other types of damage can lead cells to autodestruct through mechanisms such as apoptosis, which can elicit sequential organ failure and eventually MODS (22-26).

In the present study, we examined the effects of cardiac surgery with and without CPB on lymphopenia in children with congenital cardiac disease. We sought to determine whether lymphopenia is caused by apoptosis of $\mathrm{T}$ and/or B lymphocytes, which is of relevance since it allows us to know a possible mechanism of lymphocyte reduction.

\section{Patients and methods}

Patients. The study included for 2 years, all children with congenital heart disease who required cardiac surgery with and without CPB, who were treated at the Pediatric Hospital of the Siglo XXI National Medical Center of the Mexican Institute of Social Security in Mexico City. During this period of time, the group of children that required CPB was greater than the one that did not require it. The control group was the children without bypass. Patients $\geq 15$ years of age, with any autoimmune disease, diabetes, cancer or who had received previous treatment with anticoagulants, were excluded from the study. Sixty-eight patients with congenital cardiopathy needing surgery were studied: 53 who received the surgery with $\mathrm{CPB}$ and 15 without $\mathrm{CPB}$. There were 30 girls and 38 boys (male-to-female ratio 1.2:1) and their average age was 44.6 months. The present study has been approved by the Ethics Committee of the Health Research Commission by Dr Zamira Apis Hernández (approval no. 2005-3603-0022). Written informed consent was obtained from all parent or legal guardian from patients prior to enrollment in the study.

Central venous blood was taken from the central catheter in most patients; for patients without a central catheter, the samples were obtained using a venipuncture of a peripheral vein.

Blood was collected using disposable pyrogen-free syringes (Becton Dickinson, Franklin Lakes, NJ, USA) into two sterile tubes, one with heparin and the other without heparin.

Methods. The total lymphocyte count and complete blood count were measured before and after surgery. Lymphopenia was defined as a lymphocyte count $<1,000 / \mathrm{mm}^{3}$.

Peripheral blood mononuclear cells (PBMC) were isolated for quantification and cell counts using specific membrane markers to quantify the subpopulations of helper and cytotoxic T lymphocytes and B lymphocytes before, immediately after, and $24 \mathrm{~h}$ after surgery. Briefly, PBMC were isolated from central blood samples on a Lymphoprep gradient (Axis Shield, Oslo, Norway), and the concentration was adjusted to $5 \times 10^{5}$ cells/ml in RPMI 1640 medium (Life Technologies, Invitrogen, Carlsbad, CA, USA). 
The number of apoptotic lymphocytes cells was assessed using Annexin V-Fluos (BD Biosciences, San Diego, CA, USA) and flow cytometry (FACS Aria IIu, Becton Dickinson, USA). The cells were labeled with specific antibodies: Anti-CD19-allophycocyanin (APC), anti-CD3-phycoerythrin (PE), anti-CD4-PE, and anti-CD8-PE-Cy5 (BD Biosciences). Isotype controls were IgG1-PE, IgG2-APC, and IgG1k-PE-Cy5 (BD Biosciences).

The amount of serum IL-2 was measured by enzyme-linked immunosorbent assay (BD OptEIA ${ }^{\mathrm{TM}}$ Set Human IL-2 (BD Biosciences).

Sepsis was documented based on established criteria (12) and by the presence and identification of microorganisms in cultures. Clinical follow-up was completed until the patients were released from the pediatric intensive care unit or hospital.

Statistical analysis. The qualitative variables were expressed in absolute frequencies and percentages, and the quantitative variables in median and interquartile ranges. Inferential statistics were performed comparing subjects with and without extracorporeal pump using $\chi^{2}$ test in qualitative variables and Mann Whitney U in quantitative variables. To demonstrate the differences between the pre and post measurements between the groups, Wilcoxon test was used. $\mathrm{P}<0.05$ was considered to indicate statistically significant difference. All statistical analyses were performed using IBM SPSS Statistics software (v. 20; IBM Corp., Armonk, NY, USA).

\section{Results}

Demographic and clinical characteristics. Sixty-eight pediatric patients with cardiac congenital alterations needed cardiac surgery; 53 required surgery with $\mathrm{CPB}$ and 15 had surgery without CPB. There were $37(54.4 \%)$ boys and 31 (45.6\%) girls; $28(52.8 \%)$ boys and $25(47.2 \%)$ girls received $\mathrm{CPB}$, and nine $(60 \%)$ boys and six $(40 \%)$ girls did not receive CPB. The male-to-female ratios were $1.12: 1$ in patients who received $C B P$ and 1.5:1 in those who did not receive $C B P$. The median age was 34 months in the CBP group and 23 months in the non-CBP group (Table I). The most frequent cardiopathy was shunt (left-right), 64.2\% in the CBP group and $33.3 \%$ in the non-CBP group. The most frequent surgical correction was definitive repair, $96.2 \%$ in the CBP group and $66.7 \%$ in the non-CBP group.

Blood count. Neutrophil count in patients with CPB increased significantly $(\mathrm{P}=0.001)$, immediately after surgery and counts of lymphocytes decreased significantly (Table II). In the non-CPB group, neutrophil counts also increased significantly, and lymphocyte and monocytes counts decreased significantly after surgery (Table II).

Apoptosis of $B$ and $T$ lymphocytes. We next determined whether the decrease in lymphocyte count observed in patients undergoing cardiac surgery with or without $\mathrm{CPB}$ was caused by apoptosis of populations of $\mathrm{CD}^{+}\left(\mathrm{CD}^{+}\right.$, and $\left.\mathrm{CD}^{+}\right) \mathrm{T}$ lymphocytes, and $\mathrm{CD} 19^{+} \mathrm{B}$ lymphocytes. The percentage of apoptotic $\mathrm{B}\left(\mathrm{CD} 19^{+}\right)$lymphocytes was higher in patients who underwent surgery without $\mathrm{CPB}$ than in those who received CPB ( $\mathrm{P}=0.0001)$. The percentage of apoptotic cells before surgery was from 14 to $0 \%$ without and with CPB respectively. This percentage was slightly but not significantly higher $24 \mathrm{~h}$ after surgery in both groups (Fig. 1A).

The percentage of apoptotic $\mathrm{CD}^{+} \mathrm{T}$ lymphocytes before surgery was similar in both groups (34\%). This percentage increased slightly after surgery but decreased $24 \mathrm{~h}$ later; none of these changes were significant $(\mathrm{P}=0.2$; Fig. 1B). Apoptosis affected $25 \%$ of $\mathrm{CD}^{+} \mathrm{T}$ lymphocytes in without $\mathrm{CPB}$ group before surgery, and this percentage was significantly lower in the CPB group (2\%). The percentage of apoptotic $\mathrm{T}\left(\mathrm{CD} 4^{+}\right)$ lymphocytes was higher in patients who underwent surgery without $\mathrm{CPB}$ than in those who received $\mathrm{CPB}(\mathrm{P}<0.001$; Fig. 1C). The percentage of apoptotic $\mathrm{CD}^{+} \mathrm{T}$ lymphocytes was higher in the CPB group (5\%) than in the non-CBP group (2\%; $\mathrm{P}<0.001)$. Apoptosis of $\mathrm{CD}^{+} \mathrm{T}$ lymphocytes increased non significantly immediately and $24 \mathrm{~h}$ after surgery in both groups (Fig. 1D). In Fig. S1 we shown the apoptosis analysis dot plots of one patient (patient 10), indicating percentages of apoptosis of $\mathrm{B}(\mathrm{CD} 19+)$ and $\mathrm{T}(\mathrm{CD} 3+, \mathrm{CD} 4+)$ lymphocytes pre and post-surgery with $\mathrm{CPB}$.

Clinical complications. Clinical complications developed in a higher percentage of patients in the CPB group (71.3\%) than in the non-CPB group (60\%). A lower percentage of patients in the CPB group developed SIRS [25 (47.2\%) vs. 10 (66.7\%)]. Importantly, sepsis occurred only in the CPB group [7 patients $(13.2 \%)]$. Seven patients (13.2\%) died after surgery with CPB, two because of sepsis (28.6\%). Thirteen patients in the CPB group $(24.5 \%)$ but only two patients in the non-CPB group $(13.3 \%)$ exhibited cardiogenic shock (Table I).

Sepsis and mortality. The microorganisms isolated are listed in Table III. Seven patients in the CPB group (13.2\%) died after surgery (Table I); two (28.6\%) died of sepsis and five (20.0\%) died of SIRS. By contrast, in the non-CPB group, only two patients $(10 \%)$ died of SIRS (Table I). The mortality rate was similar in both groups (13.2 and $13.3 \%$ in the CPB and non-CPB groups, respectively). The mortality rate was higher in boys $(85.7 \%)$ than in girls $(14.3 \%)$ in the CPB group.

Interleukin-2. Serum concentration of IL-2 was of 5 to $9 \mathrm{pg} / \mathrm{ml}$, did not change significantly from before to immediately and $24 \mathrm{~h}$ after surgery and did not differ significantly between groups (data not shown).

\section{Discussion}

Despite advances in technology and the development of surgery to correct congenital heart defects, cardiopathy still occurs at a rate of 5.2 to 12.5 per thousand live births in the pediatric population. Currently in Mexico, six in 1,000 live births per year present with congenital cardiopathy disease (1). It was previously thought that lymphopenia in these patients is caused by the exclusive use of CPB secondary to the effects of ischemia-reperfusion. The devices used in surgery for these patients have evolved with advances in technology. However, this situation continues because of factors occurring during surgery, such as severe hypothermia, aortic cross-clamping, duration of $\mathrm{CPB}$, metabolic response to trauma, hypoxia, or sudden changes in temperature. Other factors may also be 
Table I. Patient information.

\begin{tabular}{|c|c|c|c|c|c|c|c|}
\hline \multirow[b]{2}{*}{ Characteristic } & \multicolumn{2}{|c|}{ Total, $\mathrm{n}=68$} & \multicolumn{2}{|c|}{ Without CPB, n=15 } & \multicolumn{2}{|c|}{ With $\mathrm{CPB}, \mathrm{n}=53$} & \multirow[b]{2}{*}{ P-value } \\
\hline & Frequency & $\%$ & Frequency & $\%$ & Frequency & $\%$ & \\
\hline Sex & & & & & & & 0.08 \\
\hline Male & 37 & 54.4 & 9 & 60.0 & 28 & 52.8 & \\
\hline Female & 31 & 45.6 & 6 & 40.0 & 25 & 47.2 & \\
\hline Age (months) ${ }^{\mathrm{a}}$ & 33 & $(10.5-61)$ & 23 & $(12-30)$ & 34 & $(9-62)$ & 0.05 \\
\hline Weight $(\mathrm{kg})^{\mathrm{a}}$ & 11.1 & $(7.6-18)$ & 11 & $(8-19)$ & 11.2 & $(6.8-18)$ & 0.70 \\
\hline Size $(\mathrm{cm})^{\mathrm{a}}$ & 87 & $(65.5-110)$ & 84 & $(66-110)$ & 88 & $(66-110)$ & 0.80 \\
\hline Extracorporean derivation time (min) & & & & & 105 & $(87-125)$ & \\
\hline Type of congenital heart disease & & & & & & & 0.002 \\
\hline Right ventricle obstruction outflow & 21 & 30.9 & 4 & 26.7 & 17 & 32.1 & \\
\hline Shunt (left-right) & 39 & 57.4 & 5 & 33.3 & 34 & 64.2 & \\
\hline Anomaly connection pulmonary veins & 4 & 5.9 & 3 & 20.0 & 1 & 1.9 & \\
\hline Left outflow obstruction & 4 & 5.9 & 3 & 20.0 & 1 & 1.9 & \\
\hline Procedure & & & & & & & 0.001 \\
\hline Palliative & 7 & 10.3 & 5 & 33.3 & 2 & 3.8 & \\
\hline Definitive repair & 61 & 89.7 & 10 & 66.7 & 51 & 96.2 & \\
\hline \multicolumn{8}{|l|}{ Complications } \\
\hline SIRS (yes) & 35 & 51.5 & 10 & 66.7 & 25 & 47.2 & 0.7 \\
\hline Sepsis or septic shock (yes) & 7 & 10.3 & 0 & 0.0 & 7 & 13.2 & 0.7 \\
\hline Cardiogenic shock (yes) & 15 & 22.1 & 2 & 13.3 & 13 & 24.5 & 0.7 \\
\hline MODS (yes) & 6 & 8.8 & 1 & 6.7 & 5 & 9.4 & 0.8 \\
\hline Mortality & 9 & 13.2 & 2 & 13.3 & 7 & 13.2 & 0.9 \\
\hline
\end{tabular}

${ }^{a}$ Median (percentile 25-percentile 75), Test U Mann Whitney. CPB, cardiopulmonary bypass; SIRS, systemic inflammatory response syndrome; MODS, multiple organ dysfunction syndrome.

Table II. Complete blood count.

\begin{tabular}{|c|c|c|c|c|c|c|c|c|c|}
\hline \multirow[b]{2}{*}{ Cell $/ \mathrm{mm}^{3}$} & \multicolumn{3}{|c|}{ Without CPB } & \multirow[b]{2}{*}{$\begin{array}{l}\text { P-value } \\
\text { (paired) }^{\mathrm{a}}\end{array}$} & \multicolumn{3}{|c|}{ With CPB } & \multirow[b]{2}{*}{ P-value ${ }^{b}$} & \multirow[b]{2}{*}{$\begin{array}{l}\text { P-value } \\
\text { (paired) }^{\mathrm{a}}\end{array}$} \\
\hline & Median & $\begin{array}{c}\text { Percentile } \\
25\end{array}$ & $\begin{array}{c}\text { Percentile } \\
75\end{array}$ & & Median & $\begin{array}{c}\text { Percentile } \\
25\end{array}$ & $\begin{array}{c}\text { Percentile } \\
75\end{array}$ & & \\
\hline Neutrophils pre & 4.0 & 3.0 & 5.8 & 0.001 & 3.5 & 2.3 & 5.1 & 0.02 & 0.001 \\
\hline Neutrophils post & 9.9 & 6.0 & 13.9 & & 8.3 & 5.0 & 10.5 & & \\
\hline Lymphocytes pre & 3.1 & 1.9 & 4.6 & 0.001 & 3.5 & 2.5 & 4.8 & 0.40 & 0.0001 \\
\hline Lymphocytes post & 1.5 & 0.9 & 1.9 & & 1.6 & 1.1 & 2.1 & & \\
\hline Monocytes pre & 0.7 & 0.4 & 1.1 & 0.03 & 0.7 & 0.6 & 1.0 & 0.04 & 0.7 \\
\hline Monocytes post & 1.1 & 0.5 & 1.2 & & 0.6 & 0.3 & 1.0 & & \\
\hline Eosinophils pre & 0.2 & 0.1 & 0.49 & 0.6 & 0.2 & 0.1 & 0.3 & 0.70 & 0.7 \\
\hline Eosinophils post & 0.0 & 0.0 & 0.01 & & 0.0 & 0.0 & 0.05 & & \\
\hline Basophils pre & 0.0 & 0.0 & 0.10 & 0.7 & 0.1 & 0.0 & 0.1 & 0.90 & 0.8 \\
\hline Basophils post & 0.0 & 0.0 & 0.001 & & 0.0 & 0.0 & 0.01 & & \\
\hline
\end{tabular}

${ }^{\mathrm{a}}$ Friedman test, ${ }^{\mathrm{b}} \mathrm{W}$ icoxon test. CPB, cardiopulmonary bypass .

involved, such as gene regulatory mechanisms including the responses of sepsis genes (26), stress induced by the disease and/or surgery, the patient's inherent susceptibility, and stress to hematopoietic tissue and cells, which accelerates the biological cycle and can cause cell self-destruction. Several studies of adults have reported multiple complications secondary to the use of CPB. More recent studies of children have been reported, but only up to 61 months of age. Shi et al 
A

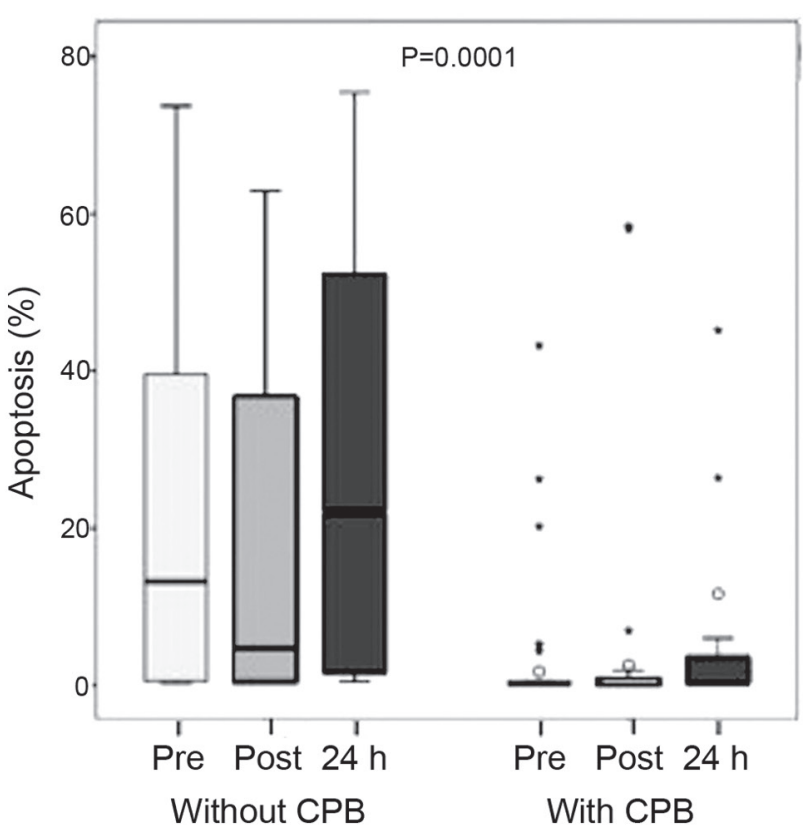

C

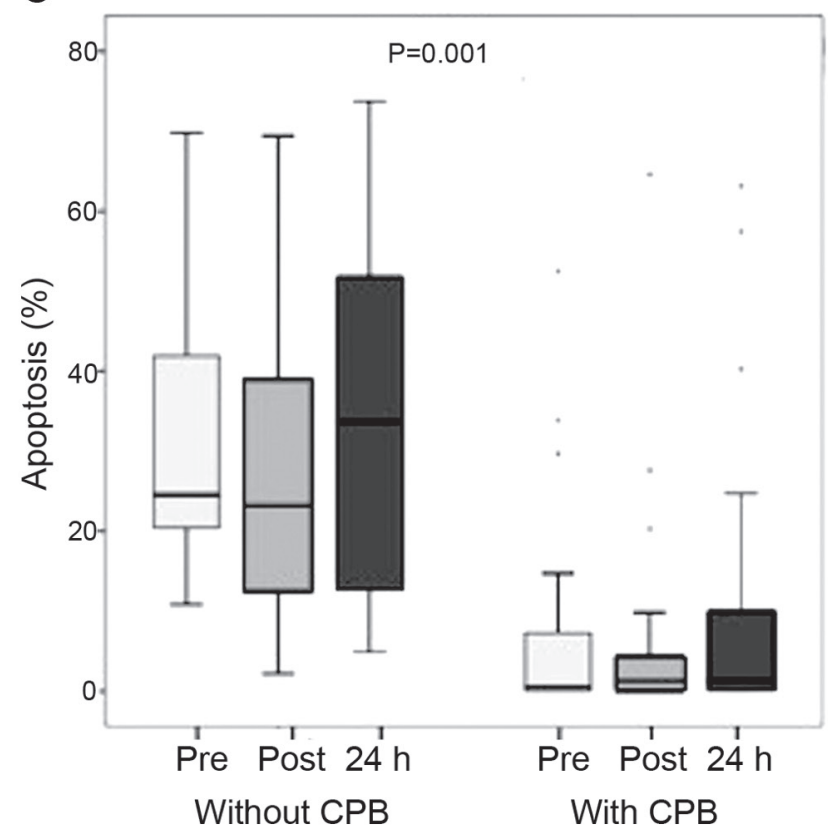

B

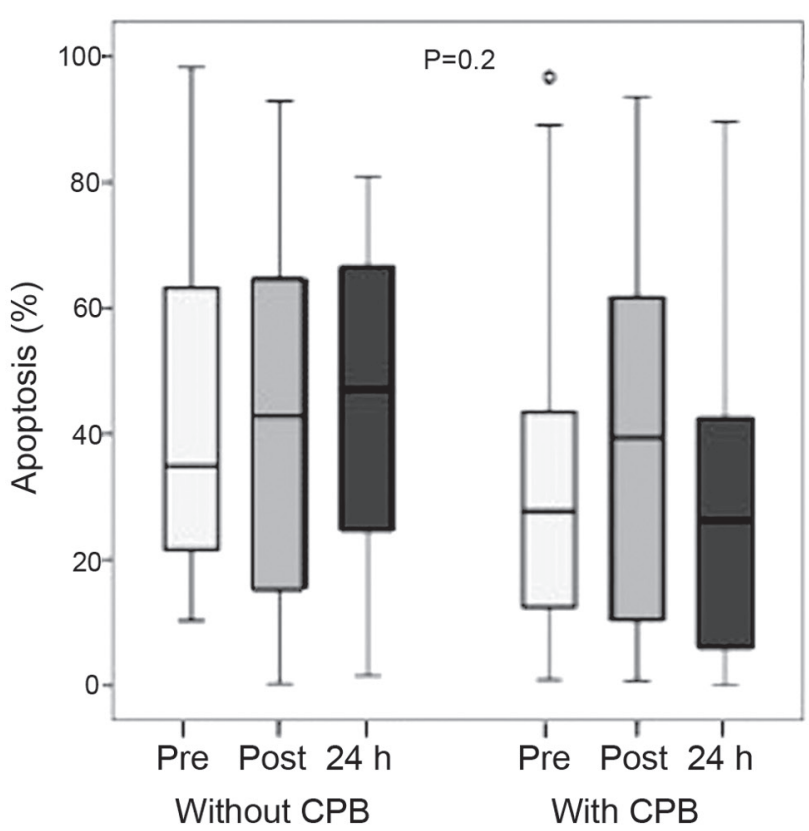

D

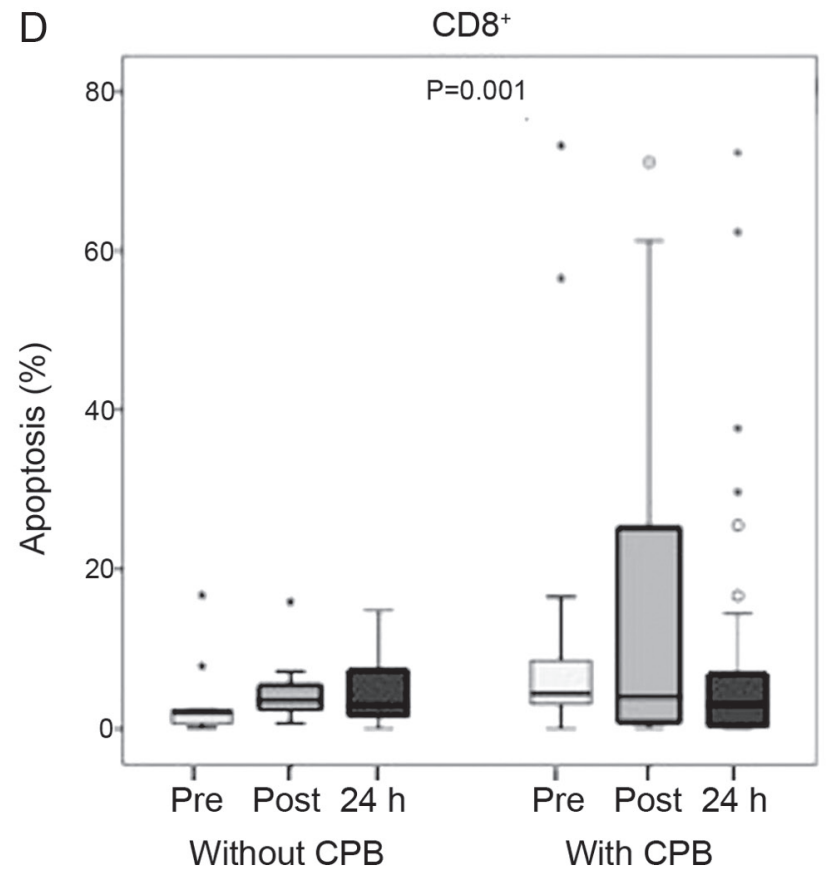

Figure 1. Apoptosis of $\mathrm{B}\left(\mathrm{CD} 19^{+}\right)$and $\mathrm{T}\left(\mathrm{CD} 3^{+} / \mathrm{CD} 4^{+}\right.$or $\left.\mathrm{CD}^{+} / \mathrm{CD}^{+}\right)$lymphocytes of patients operated on with and without $\mathrm{CPB}$. (A) Histogram of apoptosis of $\mathrm{B}$ lymphocytes before and after surgery in the $\mathrm{CPB}$ and non-CPB groups. $\mathrm{P}=0.0001$. (B) Graphic representation of apoptosis of $\mathrm{T}\left(\mathrm{CD} 3^{+}\right)$lymphocytes before and after surgery in the $\mathrm{CPB}$ and non- $\mathrm{CPB}$ groups. $\mathrm{P}=0.02$. (C) Histogram of apoptosis of $\mathrm{T}\left(\mathrm{CD} 4^{+}\right)$lymphocytes before and after surgery in the $\mathrm{CPB}$ and non- $\mathrm{CPB}$ groups. $\mathrm{P}=0.001$. (D) Graphic representation of apoptosis of $\mathrm{T}\left(\mathrm{CD} 8^{+}\right)$lymphocytes before and after surgery in the $\mathrm{CPB}$ and non- $\mathrm{CPB}$ groups $\mathrm{P}=0.001$. $\mathrm{CPB}$, cardiopulmonary bypass.

included only pediatric patients and found decreased lymphocyte counts regardless of the use of CPB (2). Our findings support those of Shi et al.

The complete blood counts showed similar cell distributions in both groups of patients. However, despite this similarity in cell counts, they should not be considered as only one group before surgery because of differences in their presurgery physiological condition, which may influence the decision of cardiologists and surgeons about which patients need or do not need CPB.
After surgery, patients in both groups showed a significant increase in neutrophil count, which was probably caused by an immediate immune response to the damage caused by the surgery and was independent of the use of CPB. Most studies agree that the increase in neutrophil count reflects an important change in cells central to the inflammatory response and the recognition of pathogens or their ligands. By contrast, lymphocyte count decreased significantly in both groups, which was unexpected because studies of adults have reported that lymphopenia occurs only in patients undergoing 
Table III. Sepsis etiology.

A, Surgery with CPB

\begin{tabular}{lcr}
\hline Isolate microorganism & Frequency & $\%$ \\
\hline Staphylococcus sp. & 2 & 3.8 \\
Enterobacter cloacae & 1 & 1.9 \\
Escherichia coli & 1 & 1.9 \\
Enterococcus faecalis & 1 & 1.9 \\
Streptococcus pneumoniae & 2 & 3.8 \\
Cultivo negativo & 46 & 86.7 \\
Total & 53 & 100.0 \\
\hline
\end{tabular}

B, Surgery without CPB

\begin{tabular}{lcc}
\hline Isolate microorganism & Frequency & $\%$ \\
\hline Cultivo negativo & 15 & 100.0 \\
Total & 15 & 100.0 \\
\hline
\end{tabular}

$\mathrm{CPB}$, cardiopulmonary bypass.

surgery with CPB. As in our study, a previous study that included pediatric patients reported reduced lymphocyte counts in both patients operated on with and without CPB, although the decrease was greater in the CPB group $(2,27)$. In other study that included infants, it was compared the clinical effectiveness and biocompatibility of poly-2-methoxyethyl acrylate (PMEA)-coated and heparin-coated CPB circuits in elective cardiac surgery with CPB for ventricular septum defects, finding that the leukocyte counts were significantly lower 5 min after CPB in the PMEA group than the heparin group, showing that PMEA-coated circuits cause transient leukopenia during pediatric CPB (28). However, this study was different from ours, because they did not compare cardiac surgery with and without CPB and did not determine the apoptosis of the lymphocytes. We also found that the counts of all hematopoietic cell populations decreased after surgery in the CPB group, which indicated sensitivity to surgical stress in this group. Eosinophil count decreased in patients undergoing surgery without CPB. The differences in hematopoietic cell counts may reflect the inflammatory response and/or synthesis of cytokines following surgery (29). Different cytokines are produced to stimulate the production of specific hematopoietic lineages after damage to tissues (30).

The decrease in lymphocyte count may increase the risk of developing an infection, which may lead to severe sepsis, the precursor of MODS that can lead to death. In tertiary-level hospitals, sepsis remains an important issue because it is the leading cause of death in patients surgery to correct congenital heart defects; it is also the main cause of admission to postoperative therapy in heart-surgery patients. In this study, we observed a higher frequency of cardiogenic shock and sepsis in patients with CPB than in patients without CPB. However, sepsis developed only in patients who received CPB. These findings suggest the need for further understanding of the cellular, biochemical, and molecular mechanisms underlying the responses of pediatric patients who undergo surgery with CPB.

The decrease in lymphocyte count observed in our study seemed to be caused by apoptosis of B lymphocytes (CD19+) in the non-CPB group and of $\mathrm{T}$ lymphocytes $\left(\mathrm{CD}^{+}\right)$in the $\mathrm{CPB}$ group, although no significant differences were found in the rate of apoptosis of $\mathrm{B}$ and $\mathrm{T}$ lymphocytes after surgery in both groups. Several studies have reported that CPB causes cytotoxic effects in several hematopoietic lineages, such as a decreased mitogenic activity of lymphocytes or morphological changes in neutrophils $(29,31,32)$. However, it seems that the effect may be greater in certain cell lineages, although, to our knowledge, this has not been reported in any previous work. We observed increased apoptosis of $\mathrm{CD}^{+} \mathrm{T}$ lymphocytes after surgery with CPB and increased apoptosis of B lymphocytes after surgery without $\mathrm{CPB}$. The decreased number of cells may be caused by a cytostatic effect given that hematopoietic tissue is one of the most sensitive tissues to environmental changes, such as temperature changes, contact with foreign surfaces, or cell damage. It is probable that all of these factors contribute to the decreased number of hematopoietic cells. This is the first study to show that the decreased in lymphocyte count in children undergoing corrective heart surgery, with and without $\mathrm{CPB}$, may result from increased apoptosis of $\mathrm{CD}^{+} \mathrm{T}$ and $\mathrm{B}$ lymphocytes. Then, in addition to analyzing the effects of cardiac surgery with and without $\mathrm{CPB}$ in the reduction of lymphocytes in children with congenital heart disease, we sought to establish if the reduction of these lymphocytes was caused by the apoptosis of the $\mathrm{T}$ lymphocytes and $\mathrm{B}$ lymphocytes, which is of relevance since it allows us to know a possible mechanism of lymphocyte reduction.

In addition, sepsis, and cardiogenic shock were also higher in the CPB group. The rates of sepsis, cardiogenic shock and MODS were higher in patients who underwent surgery with CPB. These children also had the highest neutrophil counts and lowest lymphocyte counts after surgery.

In this study, lymphocyte count decreased after surgery in both groups, but the reason for this decrease seemed to differ between the CPB and non-CPB groups. That is, the decrease in lymphocyte count was probably related to apoptosis of $\mathrm{B}$ lymphocytes $\left(\mathrm{CD}^{+} 9^{+}\right)$in the no-CPB group but to apoptosis of $\mathrm{T}$ lymphocytes $\left(\mathrm{CD}^{+}\right)$in the $\mathrm{CPB}$ group. Apoptosis can be activated by both intrinsic and extrinsic factors and hematopoietic tissue is one of the most sensitive tissues to extrinsic factors, such as temperature changes, contact with foreign surfaces, and cell damage. These factors may be involved in the decreased number of hematopoietic cells observed after cardiac surgery in infants. However, it must be considered that the number of patients included in the groups was different, which may be a limitation of the study.

In conclusion, this is the first study to determine the effects of cardiac surgery with and without CPB on leukocyte subsets in children where it was observed that the decrease of lymphocytes can be due to the increase in the apoptosis of the $\mathrm{T}$ and B lymphocytes. The decreased lymphocyte count after heart surgery may be caused by some of the events occurring during surgery, but not necessarily the effects of CPB. Patients who received CPB exhibited a large increase in neutrophil counts and a decrease in lymphocyte, counts. These cells 
are important mediators of the inflammatory response and recognition of pathogens and/or their PAMPs. Leukocytosis seen after cardiac surgery with and without CPB may have been caused by the increase in neutrophil count. Lymphocyte count decreased after cardiac surgery in both the CPB and non-CPB groups, this probably reflects apoptosis of $\mathrm{B}$ and $\mathrm{T}$ lymphocytes in response to surgical stress and not to $\mathrm{CPB}$ by itself.

\section{Acknowledgements}

The authors would like to thank Dr Horacio Márquez González (Oficina de Apoyo a la Investigación. Hospital Infantil de México Federico Gómez) for the statistical reanalysis of the results, Dr Karla Méndez Maldonado (Instituto de Fisiología Celular-Neurociencias, Universidad Nacional Autónoma de México, Ciudad Universitaria) for the reanalysis of the apoptosis results and editing Fig. S1 and Dr Rocío Nieto Menéses (Laboratorio de Investigación en Inmunología y Proteómica. Hospital Infantil de México Federico Gómez) for editing Fig. 1.

\section{Funding}

The present study was supported by Instituto Mexicano del Seguro Social, Coordinación de Investigación en Salud, Mexico City, Mexico (grant no. FIS/IMSS/PROT/C2007/053).

\section{Availability of data and materials}

The datasets used during the present study are available from the corresponding author on reasonable request.

\section{Authors' contributions}

RJA, ERM and CMB contributed to the conception and study design. RJA and NSZ contributed to the acquisition of data. CMB, RJA and NSZ performed the cytometry analysis and interpretation of data. RTF performed the statistical analyses of the data. JZ, ASG and CR analyzed and interpreted the patient data regarding the cardiology diseases. RJA, NSZ and CMB drafted the manuscript. RJA, NSZ, ERM and CMB revised the manuscript critically for intellectual content. All authors read and approved the final manuscript.

\section{Ethics approval and consent to participate}

The present study has been approved by the Ethics Committee of the Health Research Commission by Dr Zamira Apis Hernández (approval no. 2005-3603-0022). Written informed consent was obtained from all parent or legal guardian from patients prior to enrollment in the study.

\section{Patient consent for publication}

Not applicable.

\section{Competing interests}

The authors declare that they have no competing interests.

\section{References}

1. Instituto Nacional de Estadística y Geografía (INEGI). Webpage. Available at: http://www.inegi.org.mx/. Accessed July 12, 2018.

2. Shi SS, Shi CC, Zhao ZY, Shen HQ, Fang XM, Tan LH, Zhang XH, Shi Z, Lin R and Shu Q: Effect of open heart surgery with cardiopulmonary bypass on peripheral blood lymphocyte apoptosis in children. Pediatr Cardiol 30: 153-159, 2009.

3. Laffey JG, Boylan JF and Cheng DC: The systemic inflammatory response to cardiac surgery: Implications for the anesthesiologist. Anesthesiology 97: 215-252, 2002.

4. Stark J, Gallivan S, Lovegrove J, Hamilton JR, Monro JL, Pollock JC and Watterson KG: Mortality rates after surgery for congenital heart defects in children and surgeons' performance. Lancet 355: 1004-1007, 2000.

5. Markewitz A, Faist E, Lang S, Endres S, Fuchs D and Reichart B: Successful restoration of cell-mediated immune response after cardiopulmonary bypass by immunomodulation. J Thorac Cardiovasc Surg 105: 15-24, 1993.

6. Hisatomi K, Isomura T, Kawara T, Yamashita M, Hirano A, Yoshida H, Eriguchi N, Kosuga K and Ohishi K: Changes in lymphocyte subsets, mitogen responsiveness, and interleukin-2 production after cardiac operations. J Thorac Cardiovasc Surg 98: 580-591, 1989 .

7. Chello M, Mastroroberto P, Quirino A, Cuda G, Perticone F, Cirillo $\mathrm{F}$ and Covino E: Inhibition of neutrophil apoptosis after coronary bypass operation with cardiopulmonary bypass. Ann Thorac Surg 73: 123-130, 2002.

8. Habermehl P, Knuf M, Kampmann C, Mannhardt W, Schranz D, Kuroczynski W, Wippermann CF and Zepp F: Changes in lymphocyte subsets after cardiac surgery in children. Eur J Pediatr 162: 15-21, 2003.

9. Wesche DE, Lomas-Neira JL, Perl M, Chung CS and Ayala A: Leukocyte apoptosis and its significance in sepsis and shock. J Leukoc Biol 78: 325-337, 2005.

10. Hotchkiss RS, Swanson PE, Knudson CM, Chang KC, Cobb JP, Osborne DF, Zollner KM, Buchman TG, Korsmeyer SJ and Karl IE: Overexpression of Bcl-2 in transgenic mice decreases apoptosis and improves survival in sepsis. J Immunol 162: 4148-4156, 1999.

11. Calandra T and Cohen J; International Sepsis Forum Definition of Infection in the ICU Consensus Conference: The international sepsis forum consensus conference on definitions of infection in the intensive care unit. Crit Care Med 33: 1538-1548, 2005.

12. Goldstein B, Giroir B and Randolph A; International Consensus Conference on Pediatric Sepsis: International pediatric sepsis consensus conference: Definitions for sepsis and organ dysfunction in pediatrics. Pediatr Crit Care Med 6: 2-8, 2005.

13. Szabo G, Romics L Jr and Frendl G: Liver in sepsis and systemic inflammatory response syndrome. Clin Liver Dis 6: 1045-1066, 2002.

14. Takeda $\mathrm{K}$ and Akira S: Toll-like receptors in innate immunity. Int Immunol 17: 1-14, 2005.

15. Bianchi ME: DAMPs, PAMPs and alarmins: All we need to know about danger. J Leukoc Biol 81: 1-5, 2007.

16. Guha M and Mackman N: LPS induction of gene expression in human monocytes. Cell Signal 13: 85-94, 2001.

17. Lin M and Rikihisa Y: Ehrlichia chaffeensis downregulates surface Toll-like receptors $2 / 4, \mathrm{CD} 14$ and transcription factors PU.1 and inhibits lipopolysaccharide activation of NF-kappaB, ERK 1/2 and p38 MAPK in host monocytes. Cell Microbiol 6: 175-186, 2004.

18. Opal SM: The host response to endotoxin, antilipopolysaccharide strategies, and the management of severe sepsis. Int J Med Microbiol 297: 365-377, 2007.

19. Lien E and Ingalls RR: Toll-like receptors. Crit Care Med 30 (Suppl 1): S1-S11, 2002.

20. Wang JE, Jørgensen PF, Almlöf M, Thiemermann C, Foster SJ, Aasen AO, Solberg R. Peptidoglycan and lipoteichoic acid from Staphylococcus aureus induce tumor necrosis factor alpha, interleukin 6 (IL-6), and IL-10 production in both T cells and monocytes in a human whole blood model. Infect Immun 68: 3965-3970, 2000.

21. Pålsson-McDermott EM and O'Neill LA: Signal transduction by the lipopolysaccharide receptor, Toll-like receptor- 4 . Immunology 113: 153-162, 2004.

22. Shimaoka M and Park EJ: Advances in understanding sepsis. Eur J Anaesthesiol Suppl 42: 146-153, 2008. 
23. Weigand MA, Hörner C, Bardenheuer HJ and Bouchon A: The systemic inflammatory response syndrome. Best Pract Res Clin Anaesthesiol 18: 455-475, 2004

24. Li S, Price R, Phiroz D, Swan K and Crane TA: Systemic inflammatory response during cardiopulmonary bypass and strategies. J Extra Corpor Technol 37: 180-188, 2005.

25. Day JR and Taylor KM: The systemic inflammatory response syndrome and cardiopulmonary bypass. Int J Surg 3: 129-140, 2005.

26. Castellheim A, Brekke OL, Espevik T, Harboe M and Mollnes TE: Innate immune responses to danger signals in systemic inflammatory response syndrome and sepsis. Scand J Immunol 69: 479-491, 2009.

27. Aldemir M, Baki ED, Adali F, Çarşanba G, Tecer E and Taş HU: Comparison of neutrophil:lymphocyte ratios following coronary artery bypass surgery with or without cardiopulmonary bypass. Cardiovasc J Afr 26: 159-164, 2015.

28. Itoh H, Ichiba S, Ujike Y, Douguchi T, Kasahara S, Arai S and Sano S: A prospective randomized trial comparing the clinical effectiveness and biocompatibility of heparin-coated circuits and PMEA-coated circuits in pediatric cardiopulmonary bypass. Perfusion 31: 247-254, 2016.
29. Khabar KS, elBarbary MA, Khouqeer F, Devol E, al-Gain S and al-Halees Z: Circulating endotoxin and cytokines after cardiopulmonary bypass: Differential correlation with duration of bypass and systemic inflammatory response/multiple organ dysfunction syndromes. Clin Immunol Immunopathol 85: 97-103, 1997.

30. Miller BE and Levy JH: The inflammatory response to cardiopulmonary bypass. J Cardiothorac Vasc Anesth 11: 355-366, 1997.

31. Meldrum DR: Tumor necrosis factor in the heart. Am J Physiol 274: R577-R595, 1998.

32. Hill GE: Cardiopulmonary bypass-induced inflammation: Is it important? J Cardiothorac Vasc Anesth 12 (2 Suppl 1): S21-S25, 1998.

(ic)(-) This work is licensed under a Creative Commons Attribution-NonCommercial-NoDerivatives 4.0 International (CC BY-NC-ND 4.0) License. 